\title{
The Prevalence of OSMF among Biscuit Factory Workers in Delhi NCR Region: A Cross-Sectional Study
}

\author{
KHATEEB KHAN', MANSIMRANJIT KAUR UPPAL ${ }^{2}$, SALONI DEOL JAIN 3
}

INTRODUCTION: The consumption of tobacco and related products is on the rise and promotes various medical/oral conditions that leads to increased morbidity/mortality in people.

AIM: To assess the prevalence of Oral Submucous Fibrosis (OSMF) among biscuit factory workers in Delhi NCR region, India MATERIALS AND METHOD: A total of 496 biscuit factory workers in Delhi NCR region, were interviewed and examined for OSMF and associated lesions with the help of a preformed, pre-tested questionnaire. The population was divided into four stratas according to age ( $\leq 34$ years, $35-44$ years, $45-60$ years and $>60$ years). Data was entered into Microsoft Excel. Descriptive statistics were applied and statistics (t-test) was done using SPSS 19.0.

RESULTS: OSMF was observed in 173(34.9\%) [ males $116(23.4 \%)$, females 57(11.5\%)] and the difference was statistically significant $(\mathrm{p}=\mathrm{0.02})$. The majority of subjects having OSMF $(48,27.8 \%)$ were seen in the age group of $\leq 34$ years. Male: Female predilection was observed as 2.03

CONCLUSION: Efforts and strategies need to be directed to reduce the overall consumption of tobacco and related products in both urban and rural areas.

KEYWORDS: Prevalence, Oral Submucous Fibrosis, Arecanut, Tobacco

\section{INTRODUCTION}

Oral Submucous Fibrosis (OSMF), has highest malignant potential as compared to oral premalignant lesions and is found with a female predilection (although it varies from region to region) and is associated with areca nut chewing. Other contributory factors include chillies, lime, tobacco, nutritional deficiencies such as iron and zinc, immunological disorders, and collagen disorders. ${ }^{1}$ This condition mainly is seen in the Indian subcontinent and South-east Asian countries with authors finding its incidence in countries like UK, China, Saudi Arabia, Kenya and can be attributed to the migration of these habitual tobacco chewers in these countries. ${ }^{2,3}$

The consumption of Areca nut and associated substances could be due to lack of awareness and education among people, which usually belong to people from low socio-economic status. ${ }^{4}$ Authors have reported that these people are not aware of the potential and life-threatening harmful effects associated with the use of these substances and are consumed for perceived beneficial effects which include mouth freshening to aid in digestion and most of all mood enhancement/stress relief. 5 Shah $\mathrm{G}$ et al. have stated that the use of paan and gutkha is difficult to control in most countries where it is widespread, with their excessive and extensive use leading to oral cancer as people become habitual to it and find it difficult to leave this habit. ${ }^{6}$

Considered as a psychoactive substance, arecanut is commonly known as "supari" in India. It is important to note that India is also the largest producer and consumer of areca nut in the world. ${ }^{7}$ Overall prevalence rates of OSMF in India vary between $0.2-0.5 \%$, with a gender-wise prevalence of 0.2-2.3\% in males and 1.2-4.57\% among females. ${ }^{8}$ It also has a high risk of Malignant transformation (4.5 to $7.6 \%$ ) and therefore, constant screening of people vulnerable to OSMF with provision of habit breaking techniques, education and motivating must be constantly provided to them. This study hence, was conducted to assess the prevalence of OSMF among biscuit factory workers in Delhi NCR region, India.

\section{MATERIALS AND METHODS}

The present study, which was Cross- sectional in nature, was conducted among various biscuit factory workers in Delhi NCR region from June 2017 to November 2017. The study population comprised of a total of 496 biscuit factory workers, who were examined and interviewed with the help of a 
preformed, pretested questionnaire that enquired their habits and their sign and symptoms associated with OSMF. They were further divided according to four age strata, that were, $\leq 34$ years, $35^{-} 44$ years, 4560 years and $>60$ years. Workers giving a history of any systemic disease were excluded from the study. An informed, written consent in hindi was obtained from the workers after explaining them about the aims and objectives of the study. Efforts were made to include a homogeneous, convenient sample of biscuit factory workers from Delhi and adjoining states that comprise of the National Capital Region (NCR), India. The examinations were carried out by three examiners with four recording clerks who entered the data in the questionnaire. The examiners and the instruments were standardized and calibrated according to the current norms. The examinations were conducted according to ADA type III examination under natural light.

A diagnosis of OSMF was made when the subject showed tell-tale signs of OSMF, with those being blanching and stiffness of the oral mucosa, any presence of palpable bands in buccal and/or labial mucosa, and having discomfort in mouth opening and tongue protrusion. The armamentarium used for this were sterile mouth mirrors, explorers, tweezers, kidney trays, instrument pouches, disposable latex gloves, disposable mouth masks and questionnaires, which were duly sterilized and placed in sealable pouches one day prior to every examination. Statistical analysis (t-test) was done using SPSS version 19.0. ${ }^{9}$

\section{RESULTS}

The total study population comprised of 496 individuals, out of which $63.1 \%$ (313) were males and $36.9 \%$ (183) were females. OSMF was observed in 173 workers $(34.9 \%)$, and out of them, a total of 116 were males (23.4\%) and 57 were females (11.5\%). A statistically significant difference $(\mathrm{p}=\mathrm{0.02})$ was found between workers affected with OSMF and those without OSMF (non-tobacco users) [Table 1].

Table 2. depicts the distribution of OSMF among different age groups. Alarmingly, the highest percentage of OSMF was seen in people belonging to $\leq 34$ years $(48,27.8 \%)$, closely followed by $>60$ years $(47,27.2 \%)$. The least OSMF was seen among the remaining two groups 39, $(22.5 \%)$, and the differences between the age groups was nonsignificant.

\section{DISCUSSION}

In the present study, the prevalence of OSMF among biscuit factory workers in Delhi NCR region, India was $34.9 \%$ which is in agreement with Agrawal A et al. $(34.1 \%)^{10}$, but in disagreement to Neufled et al. $(16.2 \%)^{11}$, Patwardhan $\mathrm{N}$ et al. $(8.9 \%)^{12}$, Jain $\mathrm{M}$ et al. $(1.04 \%)^{13}$. One reason for this high prevalence could be that workers in the biscuit factory find their work to be dull and repetitive, and therefore, consume tobacco to divert their mind. Secondly, the presence of peer motivation, i.e seeing the other using tobacco products could have led others to also start consuming tobacco products. Thirdly, difference in individual perceptions and differences in geographical variation could have also attributed to such a high percentage of this condition.

In the present study, it was found that OSMF was common in $\leq 34$ years $(48,27.8 \%)$ old workers followed by $>60$ year old workers $(47,27.2 \%)$. These findings are in agreement to Patwardhan $\mathrm{N}$ et al. [25-34 years (36.04\%)] $]^{12}$, and Sharma $R$ et al. [42.2\% in 15 -24 year olds $]^{14}$. These results also draw our attention to the fact that the incidence of this condition is on the rise with Singh $\mathrm{P}$ et al. documenting that OSMF prevalence was $2.9 \%$ in children aged 8-17 years in Nagpur, Maharashtra. ${ }^{6}$

The male:female predilection for OSMF in the present study was 2.03, which is higher in comparison to Singla R et al.(6:1) ${ }^{2}$ and Hazarey VK et al. (4.9:1) ${ }^{15}$, but in comparison to Wahab NU et al. $(1.5: 1) .{ }^{16}$

\section{CONCLUSION}

The sale of tobacco products and its use which leads to various medical and dental conditions is still a major public health challenge in India. ${ }^{17}$ Therefore, a need arises to educate the people to quit this habit and dental and medical professionals, government and NGOs' should carry nationwide screening and education programs with timely re-enforcement and subsequent motivation so as the burden of this disease is reduced.

\section{REFERENCES}

1. Das M, Manjunath C, Srivastava A, Malavika J, Ameena MVM. Epidemiology of Oral Submucous Fibrosis: A Review. Int J Oral Health Med Res 2017;3(6):126-9.

2. Singla C, Khanna R. OSMF and its Prevalence 
Amongst Rural Shop Owners in Panchkula District, Haryana, India: A Descriptive Study. Int Healthcare Res J 2017;1(1):23-7.

3. Nigam NK, Aravinda K, Dhillon M, Gupta S, Reddy S, Srinivas Raju M. Prevalence of oral submucous fibrosis among habitual gutkha and areca nut chewers in Moradabad district. Journal of Oral Biology and Craniofacial Research 2014;4(1):813.

4. Niaz K, Maqbool F, Khan F, Bahadar H, Ismail Hassan F, Abdollahi M. Smokeless tobacco (paan and gutkha) consumption, prevalence, and contribution to oral cancer. Epidemiology and Health. 2017;39:e2017009.

5. Banerjee SC, Ostroff JS, Bari S, D’Agostino TA, Khera M, Acharya S, et al. Gutka and Tambaku paan use among South Asian immigrants: a focus group study. J Immigr Minor Health. 2014;16:531-9.

6. Singh P, Mittal R, Chandak S, Bhondey A, Rathi A, Chandwani M. Prevalence of Oral Submucous Fibrosis in Children of Rural Areas of Nagpur, Maharashtra, India. Int J Prev Clin Dent Res 2016;3(4):243-5.

7. Auluck A, Hislop G, Poh C, Zhang L, Rosin MP. Areca nut and betel quid chewing among South Asian immigrants to Western countries and its implications for oral cancer screen-ing. Rural Remote Health 2009;9(2):1118.

8. Phatak A. Fibrin producing factor in Oral SubMucous Fibrosis. Indian J Otolaryngol Head Neck Surg 1979;31:103-4.

9. IBM Corp. Released 2012. IBM SPSS Statistics for Windows, Version 19.o. Armonk, NY: IBM Corp
10. Agrawal A, Chandel S, Singh N, Singhal A. Use of tobacco and oral sub mucous fibrosis in teenagers. J Dent Sci Res 2012;3(3):1-4.

11. Neufeld KJ, Peters DH, Rani M, Bonu S, Brooner RK. Regular use of alcohol and tobacco in India and its association with age, gender, and poverty. Drug Alcohol Depend 2005;7(3):283-91.

12. Patwardhan N, Thakar S, Prabhakar I, Motghare V, Chaudhry M, Kushwaha S. Prevalence of OSMF amongst factory workers in Delhi NCR: A crosssectional study. TMU J. Dent 2015;2(1):9-11.

13. Jain M, Thakar SS, Gupta P, Singh B, Deol S, Haanda S. Prevalence of OSMF Amongs Population of Greater Noida Visiting a Dental College. JOHR. 2014;5(1):14-7.

14. Sharma R, Raj SS, Mishra G, Reddy YG, Shenava $S$, Narang P. Prevalence of Oral Submucous Fibrosis in Patients visiting Dental College in Rural Area of Jaipur, Rajasthan. J Indian Aca Oral Med Radiol 2012; 24(1):1-4.

15. Hazarey VK, Erlewad DM, Mundhe KA, Ughade SN. Oral submucous fibrosis: a study of 1000 cases from central India. J Oral Pathol Med. 2007;36(1):127.

16. Wahab N, Asifali S, Khan M, Khan S, Mehdi H, Sawani A. Frequency of clinical presentation of oral submucous fibrosis. Pak J Med Dent 2014; 4(4):4853.

17. Sagotra A, Pareek J, Singh S. Prevalence of Tobacco Consumption among Local Residents of District Panchkula, Haryana. Int Healthcare Res J 2017;1(5):21-4.

\section{AUTHOR AFFILIATIONS:}

MDS (Public Health Dentistry), Private Practitioner, New Delhi

Senior Lecturer, Department of Oral Medicine and Radiology, Swami Devi Dyal Hospital and Dental College, Panchkula

Senior Lecturer, Department of Prosthodontics, Yamuna Dental College and Research, Yamunanagar, Haryana, India

\section{Corresponding Author:}

For article enquiry/author contact details, e-mail at: manuscriptenquiry.ihrj@gmail.com 


\section{LEGENDS}

\begin{tabular}{|c|c|c|c|c|}
\hline Characteristic & Males $(\mathbf{n}, \%)$ & Females(n,\%) & Total $(\mathbf{n}, \%)$ & $\begin{array}{c}\text { t-test(With } \\
\text { OSMF*Without } \\
\text { OSMF) }\end{array}$ \\
\hline Gender & $313(63.1)$ & $183(36.9)$ & $496(100)$ & \multirow{3}{*}{$\mathrm{p}=0.02$ * } \\
\hline With OSMF & $116(23.4)$ & $57(11.5)$ & $173(34.9)$ & \\
\hline Without OSMF & $197(39.7)$ & $126(25.4)$ & $323(65.1)$ & \\
\hline
\end{tabular}

Figure 1. Distribution of the Biscuit Factory Workers (Percentages Rounded off to Nearest Decimal).

\begin{tabular}{|c|c|c|c|c|}
\hline Age & Males (n,\%) & Females n,\%) & Total & t-test \\
\hline$\leq 34$ years & $33,68.7$ & $15,31.2$ & $48,27.8$ & \multirow{5}{*}{$P=1.51$} \\
\hline 35- 44 year & $15,38.5$ & $24,61.5$ & $39,22.5$ & \\
\hline $45^{-60}$ years & $35,89 \cdot 7$ & $4,10.3$ & $39,22.5$ & \\
\hline$>60$ years & $33,70.2$ & $14,29.8$ & $47,27.2$ & \\
\hline Total & $116,67.1$ & $57,32.9$ & 173,100 & \\
\hline
\end{tabular}

Table 2. Distribution of OSMF among Different Age Groups. 